\title{
A Study on Comparison of Building Energy Simulation and Measurement Results for a City Hall
}

\author{
Young-Sun Ko${ }^{1}$, Sang Tae $\mathrm{No}^{2 *}$ \\ ${ }^{1}$ Department of Architecture, Honglk University, Seoul, Republic of Korea \\ ${ }^{2}$ Department of Architectural Engineering, Korea National University of Transportation, ChungJu, \\ Republic of Korea \\ Email: yko@hongik.ac.kr, $\stackrel{*}{\text { stno@ut.ac.kr }}$
}

Received 19 January 2015; accepted 6 February 2015; published 12 February 2015

Copyright (C) 2015 by authors and Scientific Research Publishing Inc.

This work is licensed under the Creative Commons Attribution International License (CC BY).

http://creativecommons.org/licenses/by/4.0/

(c) (i) Open Access

\section{Abstract}

In recent years, the number of public office buildings which were built by the glass curtain wall increased rapidly, but through the results of the investigation of the government, these buildings have been found that the heating and cooling load is high, and showed low energy efficiency. So in this study, through energy simulation, the energy consumption of public office building was verified and measured; environment data and calculated data were compared to make more precise simulation. The heating and cooling load was calculated via EnergyPlus; building was modeled by Google SketchUp connected to EnergyPlus. The results of this study were as follows: in simulation, incident solar radiation from large curtain wall should be underestimated. And using site-measured outdoor environment data can increase accuracy of simulation result.

\section{Keywords}

Solar Radiation, Heating Cooling Load, U-Value, EnergyPlus

\section{Introduction}

\subsection{Objectives}

In recent years, the number of local government office buildings constructed with glass curtain walls has been rapidly increasing. The results of the building energy efficiency rating analysis performed by the Korea Institute

"Corresponding author.

How to cite this paper: Ko, Y.-S. and No, S.T. (2015) A Study on Comparison of Building Energy Simulation and Measurement Results for a City Hall. Journal of Building Construction and Planning Research, 3, 1-9. 
of Construction Technology showed that the energy consumptions of Y, Seongnam, and Cheonan city halls were $791.3 \mathrm{~kW} \cdot \mathrm{h} / \mathrm{m}^{2} \cdot \mathrm{yr}, 603.3 \mathrm{~kW} \cdot \mathrm{h} / \mathrm{m}^{2} \cdot \mathrm{yr}$, and $422.2 \mathrm{~kW} \cdot \mathrm{h} / \mathrm{m}^{2} \cdot \mathrm{yr}$, which were graded off-grade (less than fifth grade), off-grade, and fourth grade, respectively, and the lowest. The building energy efficiency rating system is designed to analyze the energy efficiency of newly constructed apartment houses or commercial buildings, and to determine their grade according to the energy consumption per unit area $\left(\mathrm{kW} \cdot \mathrm{h} / \mathrm{m}^{2} \cdot \mathrm{yr}\right)$ as follows: first grade, less than 300; second grade, more than 300 to less than 350; third grade, more than 350 to less than 400; and fifth grade, more than 450 to less than 500 .

A glass curtain wall can give people a feeling of comfort with its openness and spectacular appearance, but it has difficulty in preventing radiant heat and cold air from entering through the window due to its sensitivity to instantaneous climate change from the outside. Looking at the case of the same floor in a building during daylight hours in winter, the south-facing room requires air-conditioning due to the hot indoor air even in winter, whereas the north-facing room needs to be heated due to the chilly indoor air. As identified in this case, the building made with glass curtain walls eventually consumes more heating and cooling energy. Especially during the summer months when the electric energy supply and demand situation is poor, the energy problem of public buildings constructed with glass curtain walls is considered a very sensitive issue. To avoid these situations, optimum building envelope design is indispensable. But at design stage, it is very difficult to predict energy performance because there are many variables affecting energy performance such as envelope composition, window wall ratio, building direction, louvers, blinds, zoning, and etc. So, a detailed building energy simulation can be a good solution for predicting energy performance at design stage. There are many kinds of computer software for predicting building energy performance and calculated results are getting more accurate. But a gap between actual and calculated values still exists.

In this regard, this study sought to analyze energy the consumption of local government office buildings and compare actual energy consumption and calculated (simulated) value.

\subsection{Research Process}

This study was designed to investigate the difference between calculated and measured heating and cooling loads of buildings. Towards this end, Y city hall was used as the primary target; the heating and cooling loads were determined through a comparative analysis using the EnergyPlus program, after controlling weather file conditions.

Developed in the United States, EnergyPlus is a program designed for building energy analysis using dynamic simulation as a precise simulation tool. It can be used through linkage to Google SketchUp and can implement dynamic modeling of rooms (buildings) and indoor/outdoor shades (blinds).

\section{Previous Studies}

Previous studies related to the contents of this study are as follows. Gwon Young-jun et al. derived the design requirements for awnings to minimize energy consumption in buildings and devised a simple formula for the convenient design application of such requirements [1]. The length of the awning was calculated using a simple formula that considers the incidence angle of the sun, and the optimum value was derived by calculating the sum of the heating energies of awnings with different heights and lengths. Lee Hoon et al. estimated the total energy consumption of office buildings with curtain walls and calibrated the estimates via the actual energy consumption of the buildings and statistical methods [2]. Based on these data, they discussed selection methods for building envelopes that can improve building energy performance for the remodeling of office buildings with curtain wall structures, by evaluating the building energy performance in case of changes in the envelopes. Son Ji-hun et al. ranked passive elements in terms of their energy savings effects by comparing their energy savings ratios through simulation of public office buildings, and presented seven kinds of passive elements for improving the energy performance of buildings, such as replacement of windows and doors, thermal transmittance of windows, and the window area, shielding factor, awning devices, infiltration rate, and application of a greenery system [3]. Son JI-hun et al. investigated energy saving methods for public buildings in Korea [4]. They presented various technologies, such as the installation of high-insulation windows; the introduction of the BEMS system, renewable energy equipment, and heavy water treatment facilities; the use of insulating glass; highperformance insulation, and rooftop landscaping, and proposed energy-saving measures through case studies of low-energy public buildings in Korea and abroad and their annual energy consumption, based on the efficient 
identification of energy-saving standards and policies. Kim Jeong-yun et al. investigated the effects of indoor heat on buildings with curtain walls through a simulation, and analyzed methods of reducing the energy consumption of such buildings [5]. They concluded that the reduction of the heating and cooling loads by the indoor heat can improve the cost-effectiveness of the functional glass and increase the economic effects of the reduction of electric energy and the cooling energy savings.

Unlike previous studies, this study investigated actual building energy consumption data, and calculated the heating and cooling load values using the EnergyPlus program. This study also checked the reliability of the simulation by comparing the simulation results based on weather data and the actual measurements.

\section{Comparison of Measured and Calculated Values}

\subsection{Summary of the Target Building}

The Y government office building located in Y city, Gyeonggi-do, which had the lowest energy consumption among local government office buildings in 2009 and was determined to have been "off-grade" in its energy efficiency rating evaluation at the end of 2010, was selected as the target building. Table 1 shows an overview of the building.

\subsection{Modeling of the Target Building}

The target building was modeled based on the drawings of the actual building. Figure 1 shows a bird's eye view of the target building, and Figure 2 and Figure 3 show the building in the south and north directions, which were modeled using Google SketchUp for EnergyPlus simulation. The comparison of Figure 1 and Figure 2 revealed a difference between the bird's eye view and the model. That is, although the city hall, parliament building, and culture and arts center are all connected to the government office building, this study modeled only the city hall because it was the primary target. Figure 4 shows a ground plan for the work space ( 6 - 15 floors) in which various awnings will be applied inside and outside the building to compare the resulting energy consumption.

Table 2 shows the basic setting conditions in the EnergyPlus analysis. The building wall ratio, U-value, and light/equipment density were based on architectural and mechanical drawings and heating/cooling setpoint temperatures, and ventilation rate were based on guideline of Korean government.

\subsection{Comparison of Actual and Simulated Energy Usage}

Figure 5 shows the results of the comparison of the actual total energy consumption of the target building from 2007 to 2012. This total energy is consisted of heating/cooling/hot water/light energy and expressed in TOE unit. Through application of energy saving methods such as supplementary insulation, high efficiency lights, indoor setpoint temperature control and voluntary energy saving efforts, the target building reduced a large energy up to 40\% until 2012. Although this remarkable success, there are still several problems to be solved. Figure 6, Figure 7 shows the results of the comparison of the actual energy consumption in 2012 and the calculated values of the EnergyPlus $(\mathrm{E}+$ ) loads by yearly (Figure 6) and monthly (Figure 7). The actual energy consumption (only heating, cooling and lighting energy were considered) of target building in 2012 and the calculated load value in

Table 1. Overview of the target building.

\begin{tabular}{|c|c|}
\hline Location & Y city, Gyeonggi-do, Republic of Korea \\
\hline Floor/Structure & B $2^{\text {nd }}-16^{\text {th }}$ floor/SRC \\
\hline End use & Public office \\
\hline Building area & $4934.87 \mathrm{~m}^{2}$ \\
\hline Floor area & $44668.79 \mathrm{~m}^{2}$ \\
\hline Main finish material & THK24 low-e color double glass $(6 \mathrm{CL}+12 \mathrm{~A}+6 \mathrm{CL})$ THK30 granite stone finish \\
\hline Plant/HVAC System & Absorption chiller heater, Ice Storage, PTAC, Steam boiler/VAV, CAV \\
\hline
\end{tabular}


Table 2. Basic simulation input values in the EnergyPlus.

\begin{tabular}{|ccc}
\hline & Spandrel area (50\%) & $0.53 \mathrm{~W} / \mathrm{m}^{2} \cdot \mathrm{K}$ \\
\hline Curtain wall ratio and U-value & Vision area (50\%) & $3.38 \mathrm{~W} / \mathrm{m}^{2} \cdot \mathrm{K}$ \\
\hline Granite stone curtain wall U-value & $0.461 \mathrm{~W} / \mathrm{m}^{2} \cdot \mathrm{K}$ \\
Heating setpoint & $20^{\circ} \mathrm{C}$ \\
Cooling setpoint & $28^{\circ} \mathrm{C}$ \\
Ventilation rate & $0.7 \mathrm{ACH}$ \\
Light density & $10 \mathrm{~W} / \mathrm{m}^{2}$ \\
Occupancy density & $0.1 \mathrm{person} / \mathrm{m}^{2}$ \\
Equipment density & $2 \mathrm{~W} / \mathrm{m}^{2}$ \\
\hline
\end{tabular}

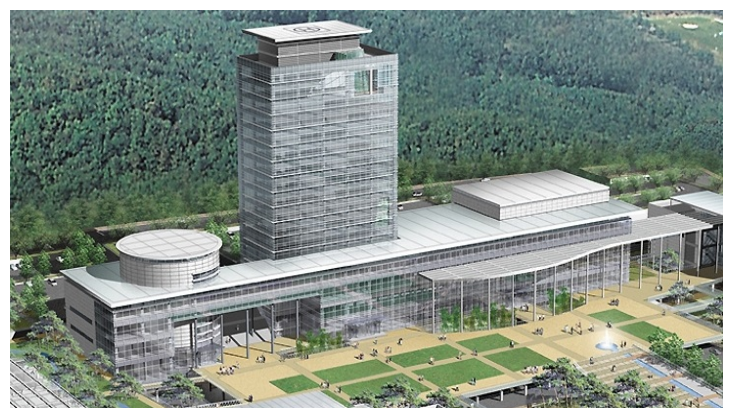

Figure 1. Perspective of the target building.

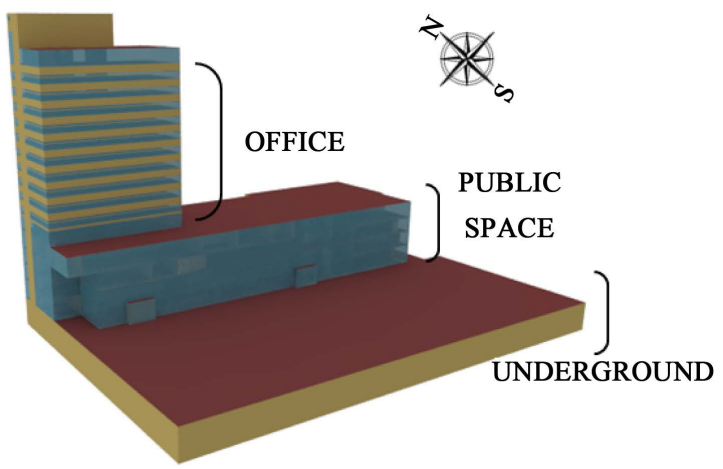

Figure 2. EnergyPlus modeling (south) and space use.

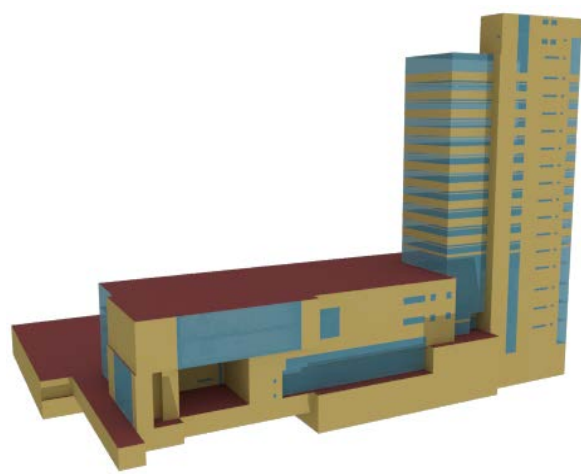

Figure 3. EnergyPlus modeling (north). 


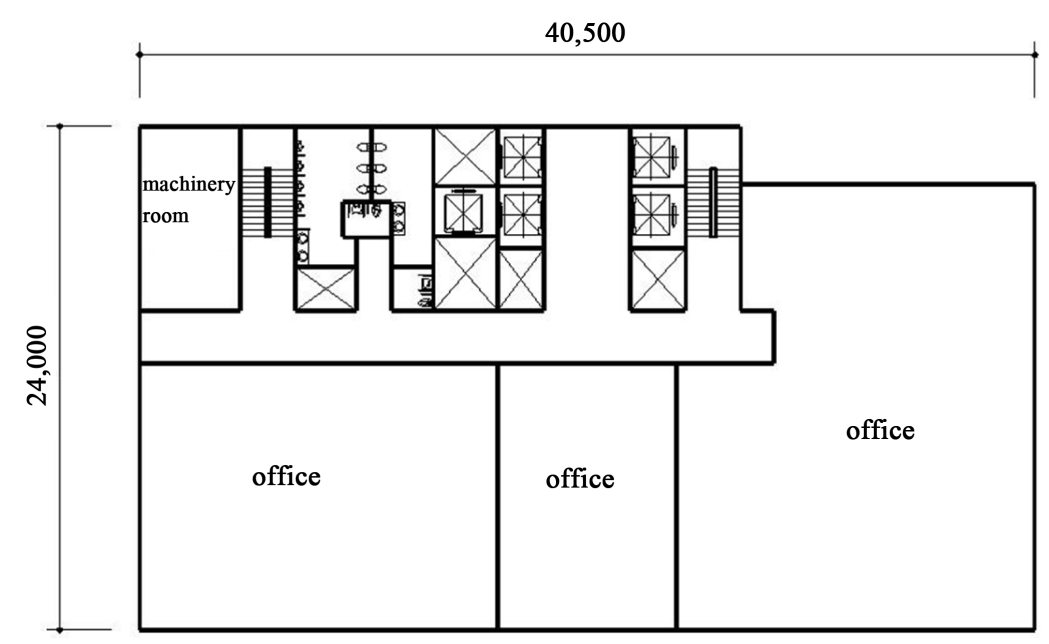

Figure 4. Typical floor plan (mm).

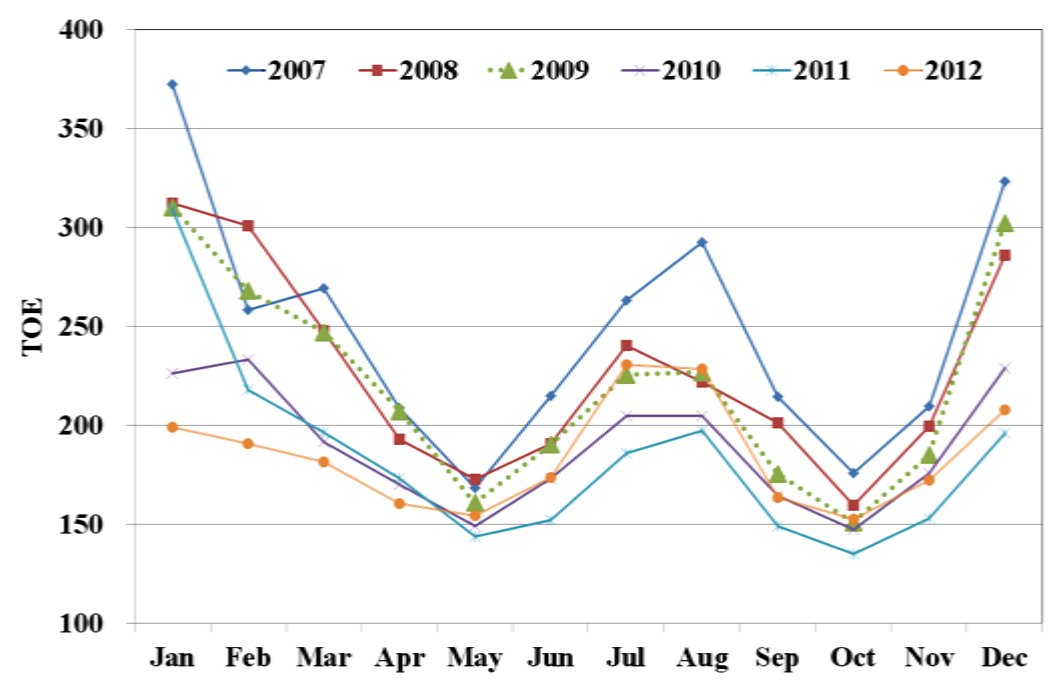

Figure 5. Actual total energy usage of the target building (2007-2012).

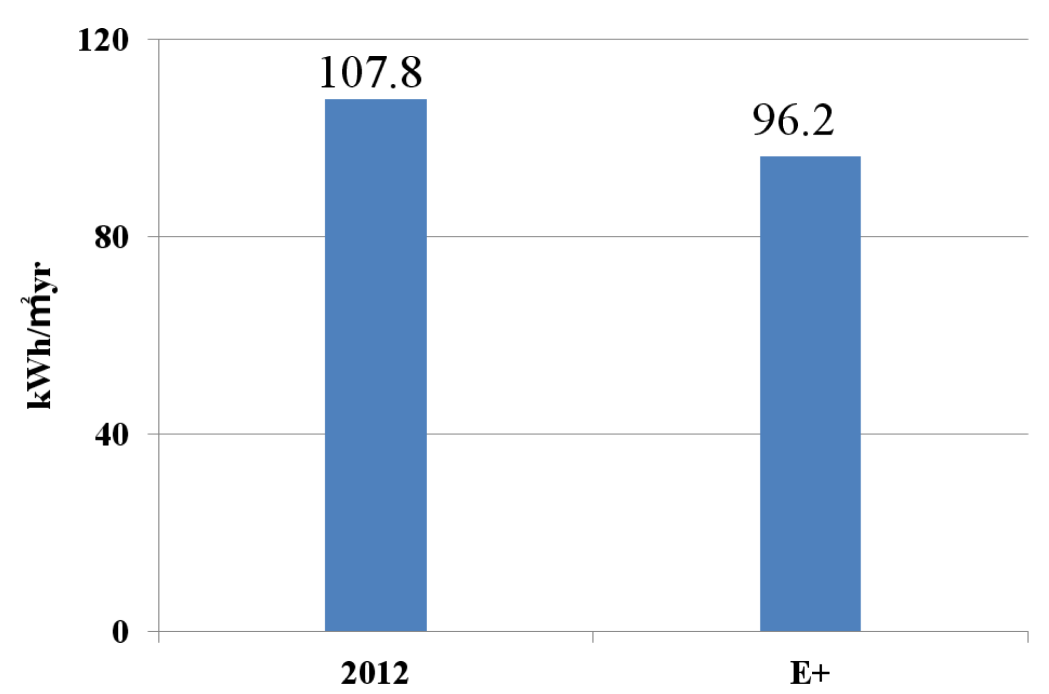

Figure 6. Actual energy usage and calculated load by yearly (2012). 


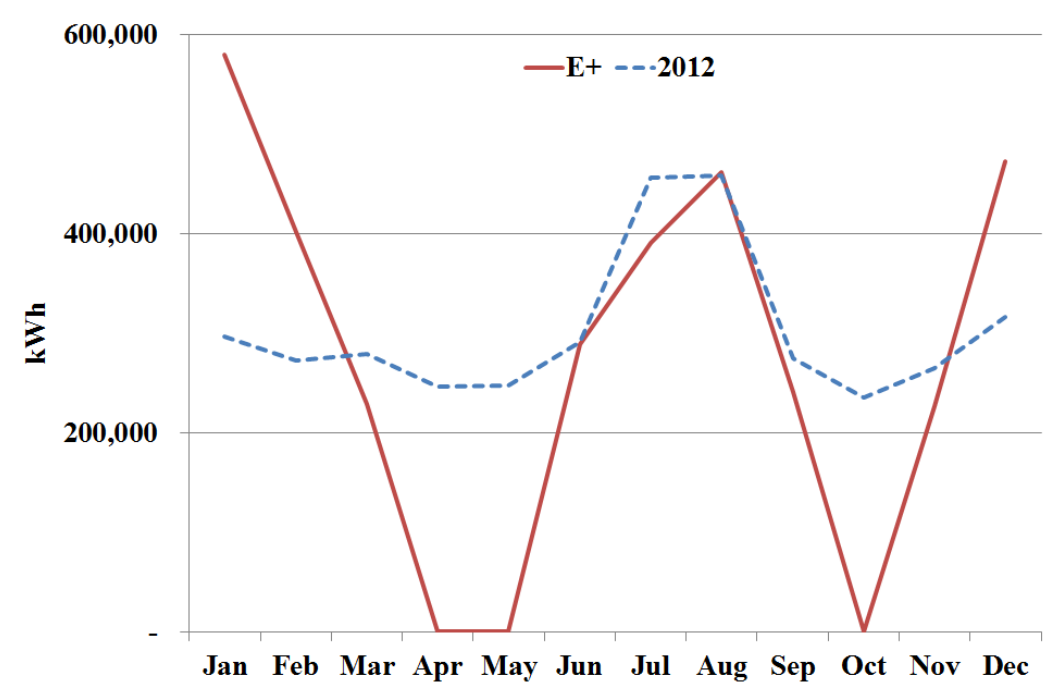

Figure 7. Actual energy usage and calculated load by monthly (2012).

EnergyPlus were $107.8 \mathrm{~kW} \cdot \mathrm{h} / \mathrm{m}^{2} \cdot \mathrm{yr}$ and $96.2 \mathrm{~kW} \cdot \mathrm{h} / \mathrm{m}^{2} \cdot \mathrm{yr}$, respectively. A relative error of $11 \%$ occurred because the EnergyPlus energy consumption is the sum of the heating/cooling loads and the lighting loads, and the actual energy consumption in 2012 included various heat losses besides the heating/cooling loads and lighting loads. As shown in Figure 7, the calculated load was higher than the actual usage in winter season. The heating load was decreased because the curtain wall of target building received lots of solar irradiations, and by the same reason, the target building used some cooling energy in spring and fall season.

\subsection{Short Term Comparison of Measured and Calculated Indoor Environment Results}

Figure 8 and Figure 9 show the measurements of the solar radiation and the humidity/temperature by the window, and the temperature/humidity at the center of the room of the target building. Figure 10 compares the measured indoor/outdoor air temperatures and calculated temperatures by $\mathrm{E}+$ during measurement period. Although measured and calculated temperatures show consistent tendency, they can't be compared by time because initial values are not same. The measured outdoor temperature, relative humidity and solar radiation are different from the weather data of $\mathrm{E}+$. So, to compare measured and calculated value precisely, we changed weather data of $\mathrm{E}+$ with measure data (8/19 10:00 - 8/23: 15:00) and simulated it again.

Figure 11 gives the result of comparison of measured temperature and calculated temperature of out and indoor building. Since the outdoor air temperature weather file was changed to measured outdoor temperature, the measured and calculated outdoor air temperature shows good match. From 9 to 18 hour, the calculated $(E+)$ indoor temperatures were fixed to $28^{\circ} \mathrm{C}$, which was indoor setpoint temperature because the indoor air temperature is ideally controlled in simulation. But the measured indoor temperatures were changed according to outdoor air temperatures from $27^{\circ} \mathrm{C}$ to $30^{\circ} \mathrm{C}$. The average relative errors between measured and calculated indoor temperature was $6.7 \%$ and the maximum error was $19.0 \%$.

Figure 12 shows the result of comparison of measured relative humidity and calculated humidity of out and indoor building. The measured outdoor relative humidity and calculated outdoor air humidity were almost equal. The measured indoor relative humidity was higher than calculated indoor relative humidity in general, because the actual indoor temperature was not stable and lower than calculated indoor temperature. But both values showed same tendency and the difference between measured and calculated relative humidity was small. The average relative error was $15.9 \%$ and the maximum error was $34.4 \%$.

Figure 13 presents the result of comparison of measured diffuse solar radiation and calculated diffuse solar radiation of out and indoor building. The outdoor diffuse solar radiation values refer to left side axis and the indoor values refer to right side axis of graph. The outdoor diffuse solar radiation also showed same values because the measured outdoor diffuse solar radiation data were inputted in $\mathrm{E}+$ weather data file. The indoor diffuse solar radiation values showed much difference between measured and calculated value. By the influence of direct solar radiation, the measured solar radiation values were much bigger than the calculated values. The avera- 


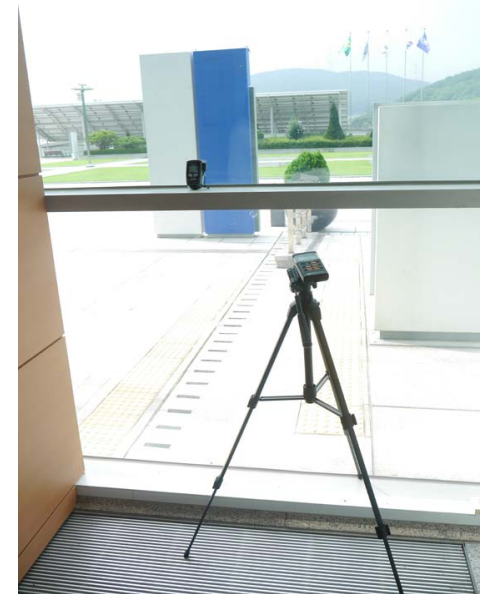

Figure 8. Measurement of solar radiation.

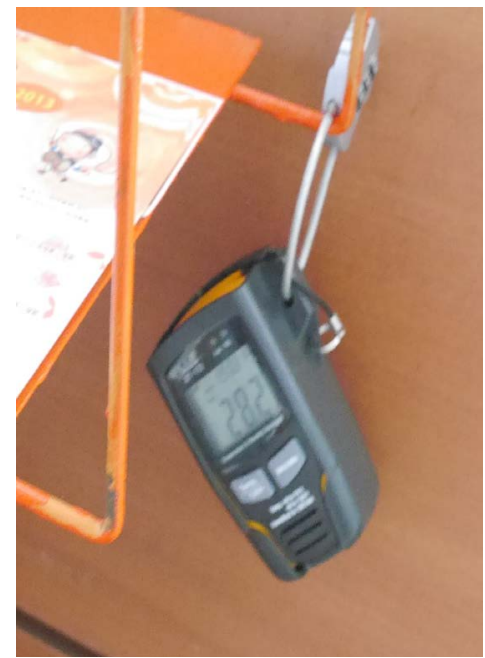

Figure 9. Measurement of indoor temperature and humidity.

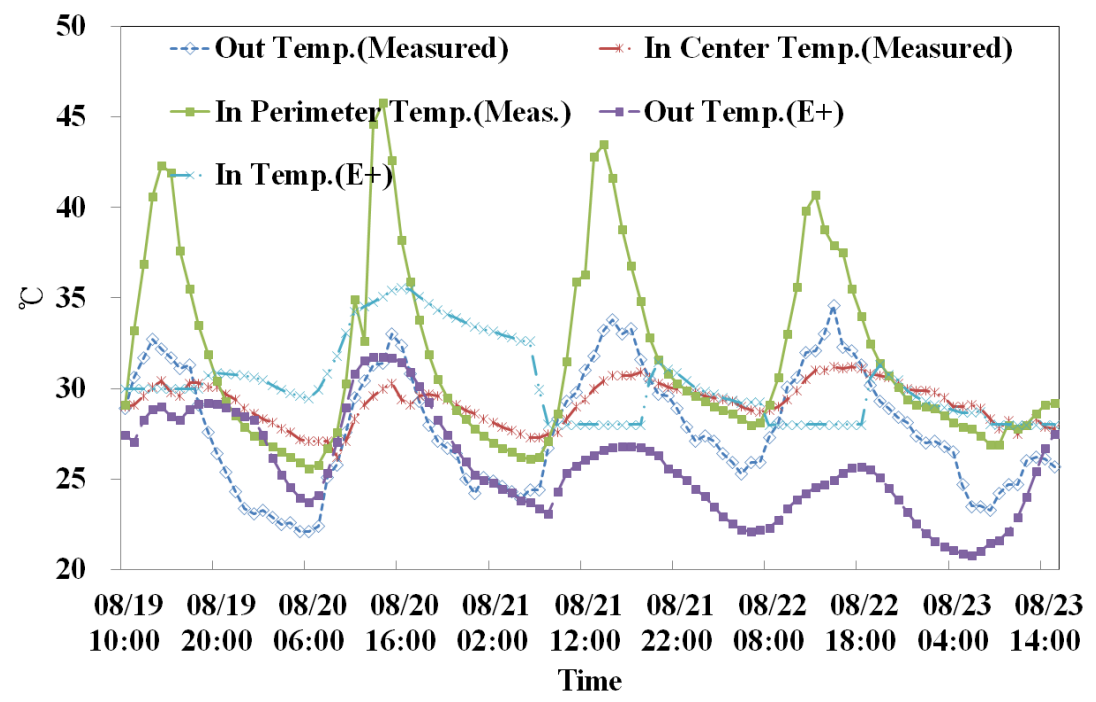

Figure 10. Comparison of measured and calculated temperature. 


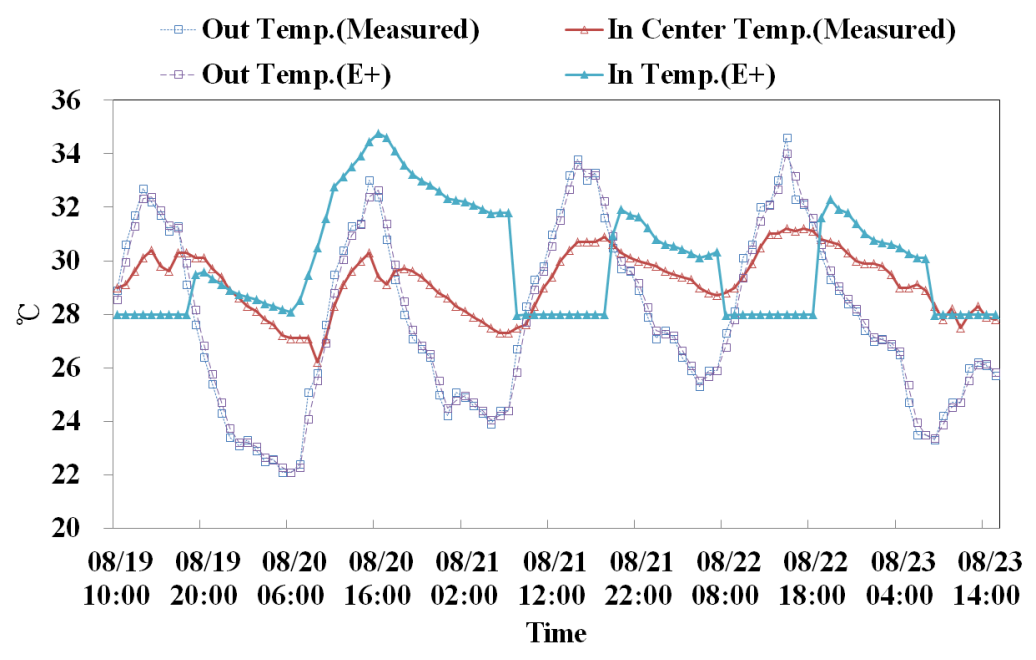

Figure 11. Comparison of measured and calculated indoor/outdoor temperature.

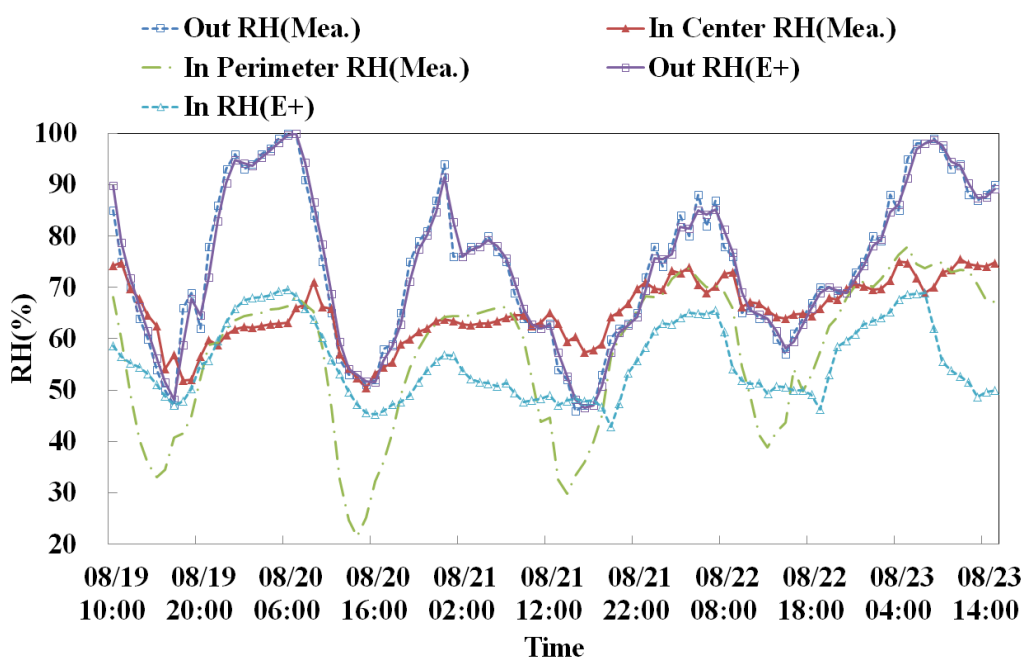

Figure 12. Comparison of measured and calculated relative humidity.

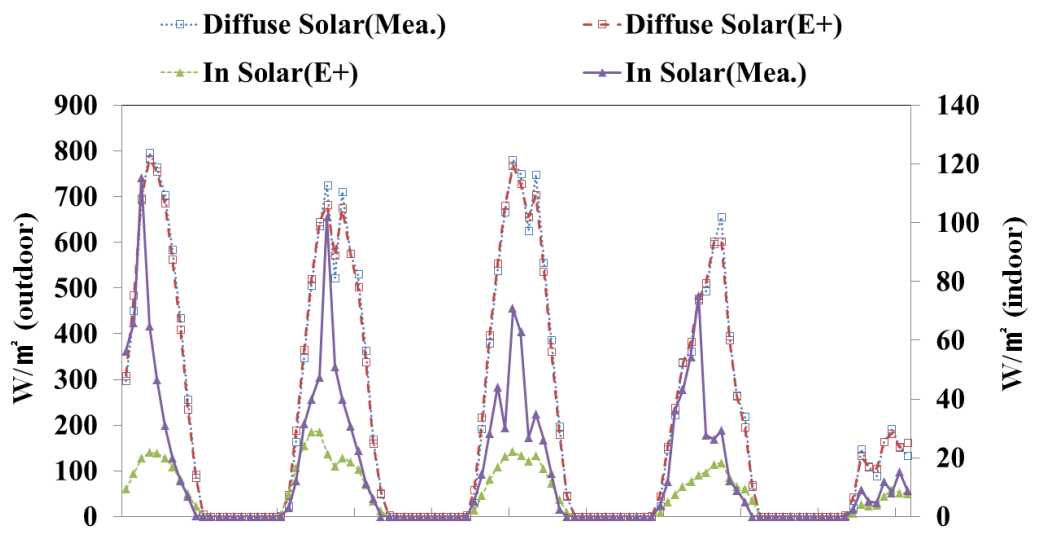

$\begin{array}{llllllllllll}08 / 19 & 08 / 19 & 08 / 20 & 08 / 20 & 08 / 21 & 08 / 21 & 08 / 21 & 08 / 22 & 08 / 22 & 08 / 23 & 08 / 23\end{array}$ 10:00 20:00 06:00 16:00 02:00 12:00 22:00 08:00 18:00 04:00 14:00

Time

Figure 13. Comparison of measured and calculated diffuse solar radiation. 
ge difference between measured and calculated indoor diffuse solar radiation was $9 \mathrm{~W} / \mathrm{m}^{2}$, and the maximum difference was $95 \mathrm{~W} / \mathrm{m}^{2}$.

\section{Conclusions}

In this study, to verify validity of EnergyPlus simulation and perform more precise simulation, we compared actual yearly energy consumption and calculated heating and cooling loads and short term indoor measured and calculated environment result using measured outdoor environment data as weather data file source for simulation.

The comparison of the EnergyPlus energy consumption and the actual yearly total energy consumption of $Y$ city hall in 2012 showed that the two values were very similar, with a relative error of $11 \%$. But monthly consumption comparison showed difference except summer season, because the target building has a large curtain wall, so heat gains from solar radiation were underestimated in simulation.

In short term comparison of measured and calculated indoor environment results, using measured outdoor environment data (temperature, relative humidity, diffuse solar radiation) as weather data for simulation, the calculated indoor temperatures showed good matches with fixed setpoint temperature, but actual measured indoor temperatures showed various values. Considering the actual HAVC system can't control indoor temperature ideally, the measured and calculated values showed good matches showing $6.7 \%$ of average relative error.

The measured indoor relative humidity was higher than calculated value because of different indoor temperature, but they also showed acceptable $15.9 \%$ of average relative error.

Measured and calculated indoor diffuse solar radiation values showed much difference because the direct outdoor solar radiation values were not measured and inputted in weather data file. This difference of solar radiation can also affect calculated indoor temperature and humidity results.

To make more precise simulation, user should set precise input conditions such as outdoor environment condition, setpoint, building operation schedule, and so on. So this study verified that site-measured outdoor environment data can calculate more reliable indoor environment results. As a further study, the method of considering outdoor direct solar radiation and comparison of results from simulation applying actual HVAC system and results from field data (same HVAC system) should be studied.

\section{Acknowledgements}

This work was supported by the Hongik University new faculty research support fund. This research was supported by 2010 Basic Science Research Program through the National Research Foundation of Korea (NRF) funded by the Ministry of Education, Science and Technology (2010-0025756).

\section{References}

[1] Kwon, Y.J., Lee, T.G., Cho, K.M. and Kim, J.H. (2011) A Study on Shading Design to Minimize Heating and Cooling Energy Demand. Korean Journal of the Korea Institute of Ecological Architecture and Environment (KIAEBS), 2011-11, 67-72.

[2] Kim, J.S., Lee, H., Oh, M.S. and Kim, H.S. (2012) A Study on Improvements of Envelope System for the Energy Saving in Curtain Wall Office Buildings. Korean Journal of KIAEBS, 6, 106-113.

[3] Son, J.H. and Kim, S. (2011) A Study on Energy Reduction of Passive Factor Apply for the Improvement of Energy Performance in Public Building. Korean Journal of the Korean Solar Energy Society, 31, 196-201.

[4] Son, J.H. and Kin, S. (2011) A Study on Energy Saving Way of Domestic Public Buildings. Korean Magazine of the SAREK, 7, 625-630.

[5] Kim, J.Y., Yook, I.S., Nam, H.J., Lee, J.S., Kim, J.M. and Cho, S. (2008) The Impact of Internal Heat Gain on Heating and Cooling Load in Curtain Wall Office Buildings. Korean Magazine of the SAREK, 6, 925-930. 
Scientific Research Publishing (SCIRP) is one of the largest Open Access journal publishers. It is currently publishing more than 200 open access, online, peer-reviewed journals covering a wide range of academic disciplines. SCIRP serves the worldwide academic communities and contributes to the progress and application of science with its publication.

Other selected journals from SCIRP are listed as below. Submit your manuscript to us via either submit@scirp.org or Online Submission Portal.
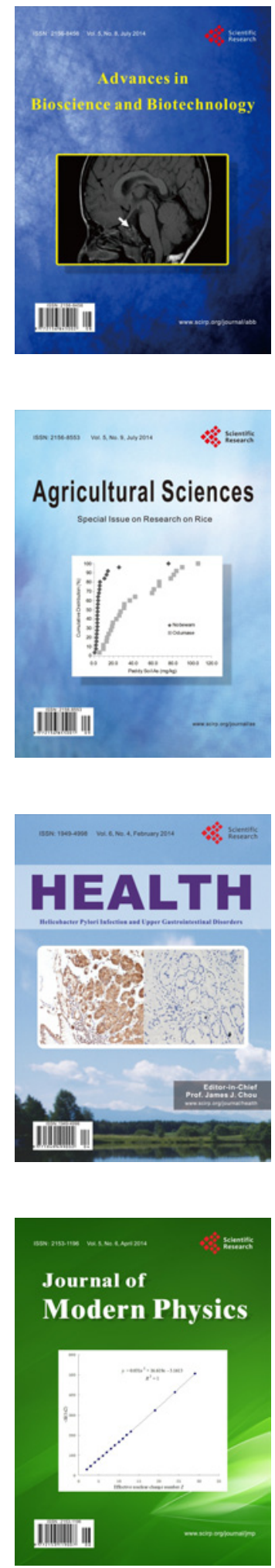
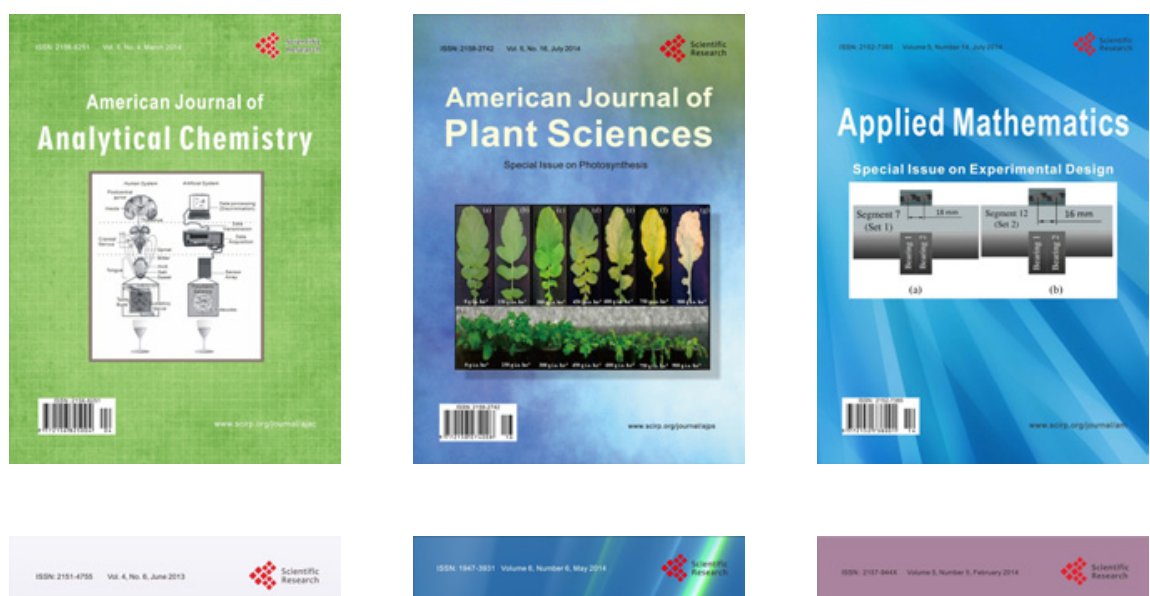

Creative Education
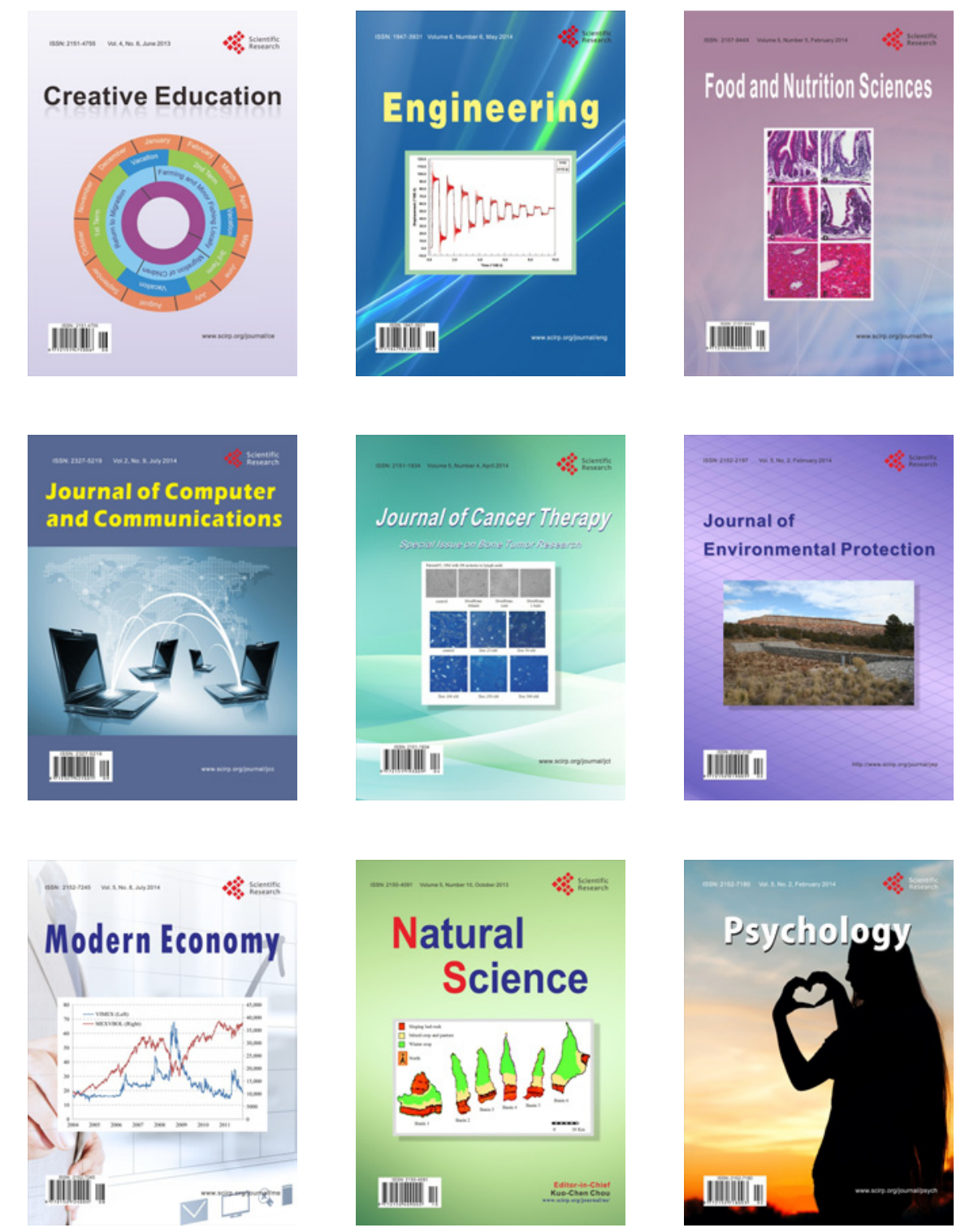